\title{
Low-band-gap, sublimable rhenium(I) diimine complex for efficient bulk heterojunction photovoltaic devices
}

\author{
H. L. Wong, L. S. M. Lam, K. W. Cheng, K. Y. K. Man, and W. K. Chan ${ }^{a}$ \\ Department of Chemistry, The University of Hong Kong, Pokfulam Road, Hong Kong, China \\ C. Y. Kwong \\ Department of Electrical and Electronic Engineering, The University of Hong Kong, Pokfulam Road, \\ Hong Kong, China
}

A. B. Djurišić

Department of Physics, The University of Hong Kong, Pokfulam Road, Hong Kong, China

(Received 25 August 2003; accepted 19 January 2004)

\begin{abstract}
The use of chlorotricarbonyl rhenium(I) diimine complex as photosensitizing molecule in photovoltaic cells is demonstrated. Unlike other transition-metal-based sensitizers, the complex is sublimable and has low band gap. It also exhibits bipolar charge transport character with relatively high carrier mobilities on the order of $10^{-3} \mathrm{~cm}^{2} \mathrm{~V}^{-1} \mathrm{~s}^{-1}$. Multilayer heterojunction and bulk heterojunction devices with fullerene as the electron accepting molecule were prepared. For the bulk heterojunction devices, the fill factor and power conversion efficiency under simulated solar light illumination were 0.56 and $0.48 \%$, respectively. Atomic force microscopic images showed that the complex dispersed evenly with fullerene molecules in solid state. (C) 2004 American Institute of Physics. [DOI: 10.1063/1.1682676]
\end{abstract}

The use of organic materials for photovoltaic cells has received considerable attention in recent years because of their great potentials in a new generation of solar cells. ${ }^{1}$ Various photovoltaic cells based on both molecular and polymeric materials have been reported. The majority of organicbased photovoltaic devices reported to date demonstrate power conversion efficiencies of less than $1 \%{ }^{2}$ One of the major hurdles in fabricating efficient organic photovoltaic cells is the insufficient exciton dissociation at low bias. In order to design an efficient organic photovoltaic cell, it is imperative that the efficiency in the dissociation of excitons and the charge transport process should be improved. We previously showed that diimine complexes based on $d^{6}$ transition metals could function as photosensitizers ${ }^{3}$ and charge transport molecules ${ }^{4}$ with bipolar character. The complexes exhibit relatively long-lived excited states with metal-toligand charge transfer (MLCT) character. Due to the presence of the heavy metal atom, the efficient spin-orbit coupling would favor intersystem crossing, which leads to the formation of long-lived triplet excited states. It is therefore envisaged that after photoexcitation, the exciton formed may have a longer lifetime so that subsequent exciton dissociation process is favored.

Here, we report the fabrication of photovoltaic cells using the chlorotricarbonyl rhenium(I) bis(phenylimino)acenaphthene (Re-DIAN) complex ${ }^{5}$ as the photosensitizer. Unlike other transition metal based photovoltaic sensitizers ${ }^{6}$ that can only be processed by solution method, this complex can be conveniently purified by sublimation under high vacuum $\left(300^{\circ} \mathrm{C}\right.$ at $10^{-5}$ mbar). Compared to other rhenium diimine complexes based on bipyridine or 1,4diaza-1,3-butadiene ligands, ${ }^{7}$ this complex has a lower band

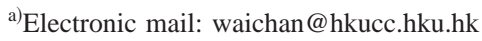

gap, which can be adjusted easily by changing the structure of the ligand. Such versatility allows the preparation of blend of metal complexes in order to broaden the sensitization region. Figure 1 shows the structure of Re-DIAN and the UVvisible absorption spectrum of its thin film. The complex exhibits a broad absorption band that covers most of the visible region in the range between 430 and $600 \mathrm{~nm}$. The maximum at $500 \mathrm{~nm}$ is assigned to be the MLCT $\left[d_{\pi}(\mathrm{Re})\right.$ to $\pi^{*}$ (DIAN)] electronic transition.

In order to determine the charge carrier mobility of the complex, a thin film $(440 \mathrm{~nm})$ of Re-DIAN sandwiched between ITO and gold electrodes was prepared. The hole and electron carrier mobilities of the complex were studied by the conventional time-of-flight experiment ${ }^{8}$ using a pulsed nitrogen laser $(337 \mathrm{~nm}$, pulse width $=4 \mathrm{~ns})$ as the light

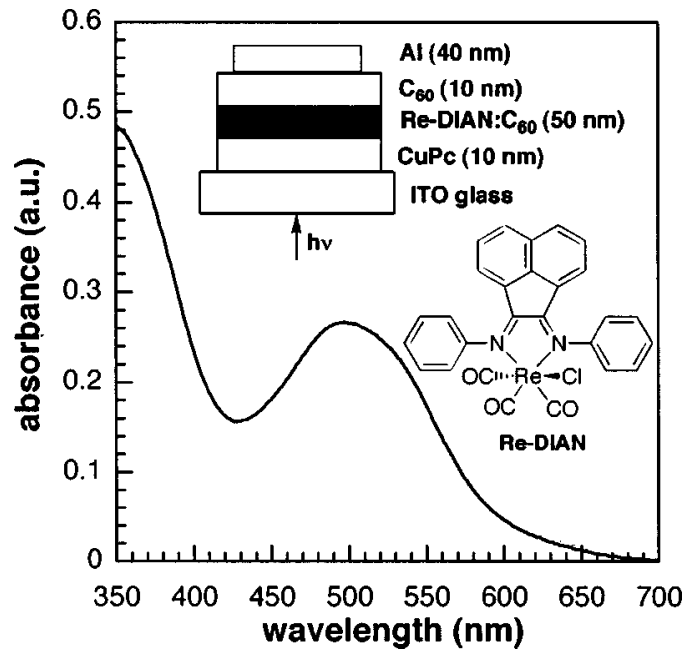

FIG. 1. Structure of the three layer photovoltaic cell and the absorption spectrum of a Re-DIAN thin film. 


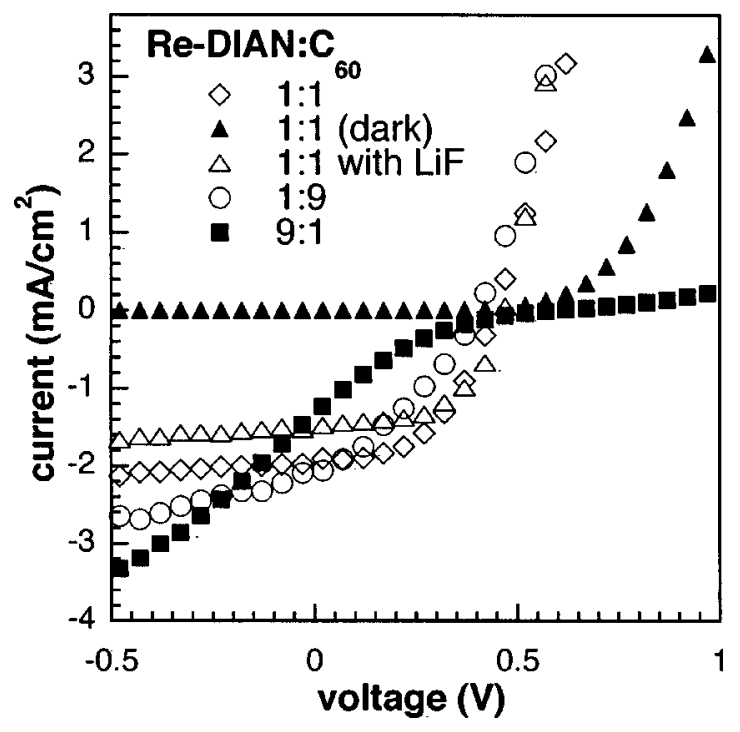

FIG. 2. Current-voltage characteristics of different photovoltaic cells in the dark or under illumination with AM1.5 simulated solar radiation.

source. The transient photocurrent profiles showed typical non-Gaussian charge transport characteristics that were dispersive in nature. The electron and hole carrier mobilities of the complex were determined to be 2.5 and 2.3 $\times 10^{-3} \mathrm{~cm}^{2} \mathrm{~V}^{-1} \mathrm{~s}^{-1}$, respectively. These results are in line with our previously reported rhenium complexes that exhibited bipolar charge transport character. ${ }^{4}$ The electron deficient DIAN ligand and the rhenium metal center may act as hopping sites for electron and hole transport, respectively.

Two types of multilayer photovoltaic devices were fabricated. The first type was multilayer heterojunction device ITO/CuPc/Re-DIAN $/ \mathrm{C}_{60} / \mathrm{Al}$ in which copper phthalocyanine $(\mathrm{CuPc})$ and fullerene were used as the hole and electron transport molecules, respectively. The second type of device consists of multilayer bulk heterojunctions $\mathrm{ITO} / \mathrm{CuPc} / \mathrm{Re}-$ DIAN: $\mathrm{C}_{60} / \mathrm{C}_{60} / \mathrm{Al}$ in which Re-DIAN and $\mathrm{C}_{60}$ were codeposited together in the same layer (Fig. 1). In this type of device, $\mathrm{C}_{60}$ molecules are able to capture electrons more efficiently once excitons are formed. ${ }^{9}$ The thickness of $\mathrm{CuPc}$, Re-DIAN (or Re-DIAN: $\mathrm{C}_{60}$ mixed layer), and $\mathrm{C}_{60}$ layers was kept at 10, 50, and $10 \mathrm{~nm}$, respectively. ITO glass slide with a sheet resistance of $20 \Omega / \mathrm{sq}$ was used as the anode and aluminum (thickness $=40 \mathrm{~nm}$ ) was used as the cathode. The highest occupied molecular orbital (HOMO) and lowest unoccupied molecular orbital (LUMO) levels of the Re-DIAN were estimated by cyclic voltammetry using ferrocene as the internal standard and they were determined to be -5.9 and $-3.7 \mathrm{eV}$, respectively, which gives rise to a HUMO-LUMO gap $E_{\text {gap }}$ of $2.2 \mathrm{eV}$. In order for an exciton to dissociate in a photovoltaic process, the band offset of donor and acceptor material must be larger than the exciton binding energy. ${ }^{10}$ From the band edge in the absorption spectrum, the optical band gap $E_{\text {opt }}$ of Re-DIAN is measured to be $2.0 \mathrm{eV}$. The exciton binding energy is estimated to be $E_{\text {gap }}-E_{\text {opt }}=0.2$ $\mathrm{eV}^{11}$ In addition, it was shown that rapid electron transfer could occur in rhenium complex with fullerene substituted bipyridine ligand. ${ }^{12}$ The lowest triplet MLCT excited state of the complex was quenched by the $\mathrm{C}_{60}$ moieties with a rate constant of $10^{8} \mathrm{~s}^{-1}$. Therefore, both the small exciton binding energy and rapid electron transfer may facilitate the subsequent exciton dissociation once excitons are formed.

The current-voltage $(I-V)$ characteristics under AM 1.5 illumination $\left(100 \mathrm{~mW} / \mathrm{cm}^{2}\right)$ of different photovoltaic devices are shown in Fig. 2, and their performance data are summarized in Table I. In the multilayer heterojunction device, the open circuit voltage $V_{\mathrm{oc}}$, short circuit current $I_{\mathrm{sc}}$, and fill factor FF were measured to be $0.58 \mathrm{~V}, 0.18 \mathrm{~mA} / \mathrm{cm}^{2}$, and 0.28 , respectively. The overall conversion efficiency of the power of the incident light into electrical power is given by the $\eta_{p}$, which is calculated according to the equation $\eta_{p}=\left(I_{\mathrm{sc}} V_{\mathrm{oc}} \mathrm{FF}\right) / P$, where $P$ is the incident light power. The $\eta_{p}$ of this device was calculated to be $0.03 \%$. The relatively poor performance may be attributed to the limitation of exciton dissociation at the Re-DIAN/ $\mathrm{C}_{60}$ junction and the lower absorption by Re-DIAN than $\mathrm{C}_{60}$. On the other hand, the photovoltaic responses were greatly improved in the cases of bulk heterojunction devices. The $V_{\mathrm{oc}}, I_{\mathrm{sc}}, \mathrm{FF}$, and $\eta_{p}$ of the device with Re-DIAN: $\mathrm{C}_{60}$ ratio=1:1 (device 3 in Table I) were $0.45 \mathrm{~V}, 1.9 \mathrm{~mA} / \mathrm{cm}^{2}, 0.56$, and $0.48 \%$, respectively. The simple three-layered Re-DIAN sensitized photovoltaic cells show improved performance compared to previously reported $\mathrm{CuPc} / \mathrm{C}_{60}$ heterojunction devices. ${ }^{13}$ It has been shown that a $\mathrm{LiF} / \mathrm{Al}$ electrode may improve the photovoltaic device efficiency by providing a good ohmic contact. ${ }^{14}$ In our case, the device with a thin layer $(0.3 \mathrm{~nm})$ of $\mathrm{LiF}$ showed no significant improvement (device 4).

The amount of photosensitizer and electron transport molecules may strongly influence the balance between the exciton formation, dissociation, and charge transport processes. The effect of changing the Re-DIAN/ $\mathrm{C}_{60}$ ratio was studied. For the device with Re-DIAN: $\mathrm{C}_{60}=1: 9$ (device 5), $V_{\mathrm{oc}}$ and $I_{\mathrm{sc}}$ values are similar, but the measured FF and $\eta_{p}$ are poorer (0.32 and $0.28 \%$ ) compared to the device with 1:1 Re-DIAN: $\mathrm{C}_{60}$ ratio. In general, low fill factor can be induced by high series resistance or by small shunt resistance. The device with Re-DIAN: $\mathrm{C}_{60}=9: 1$ shows the poorest performance among all the bulk heterojunction devices. The FF was 0.21 and its $I-V$ curve shows a concave instead of a

TABLE I. Performance of photovoltaic devices with different structures. All devices were irradiated with AM1.5 spectral illumination with power $=100 \mathrm{~mW} / \mathrm{cm}^{2}$ and device active area of $0.13 \mathrm{~cm}^{2}$.

\begin{tabular}{clcccc}
\hline \hline Device & \multicolumn{1}{c}{ Structure } & $\begin{array}{c}I_{\mathrm{sc}} \\
\left(\mathrm{mA} / \mathrm{cm}^{2}\right)\end{array}$ & $\begin{array}{c}V_{\mathrm{oc}} \\
(\mathrm{V})\end{array}$ & FF & $\begin{array}{c}\eta_{p} \\
(\%)\end{array}$ \\
\hline 1 & ITO/CuPc/Re-DIAN/C $60 / \mathrm{Al}$ & 0.18 & 0.58 & 0.28 & 0.03 \\
2 & ITO/CuPc/Re-DIAN: $\mathrm{C}_{60}(9: 1) / \mathrm{C}_{60} / \mathrm{Al}$ & 1.3 & 0.59 & 0.20 & 0.15 \\
3 & ITO/CuPc/Re-DIAN: $\mathrm{C}_{60}(1: 1) / \mathrm{C}_{60} / \mathrm{Al}$ & 1.9 & 0.45 & 0.56 & 0.48 \\
4 & ITO/CuPc/Re-DIAN: $\mathrm{C}_{60}(1: 1) / \mathrm{C}_{60} / \mathrm{LiF} / \mathrm{Al}$ & 1.5 & 0.47 & 0.56 & 0.39 \\
5 & ITO/CuPc/Re-DIAN: $\mathrm{C}_{60}(1: 9) / \mathrm{C}_{60} / \mathrm{Al}$ & 2.1 & 0.41 & 0.32 & 0.28 \\
\hline \hline
\end{tabular}




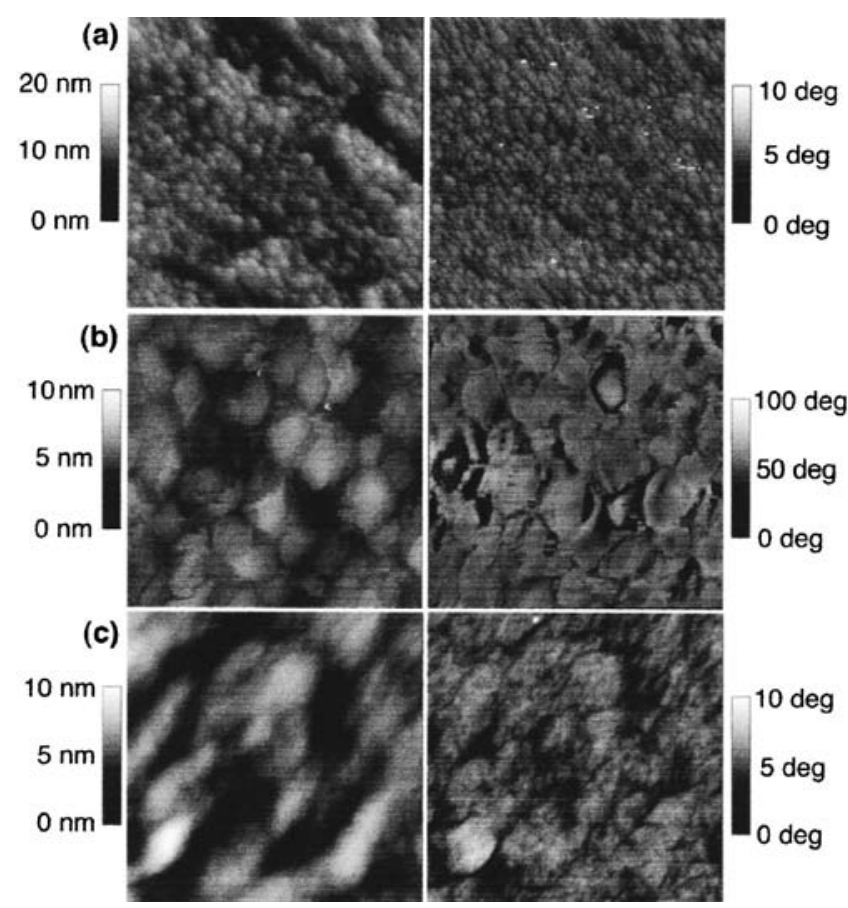

FIG. 3. Tapping mode AFM images (left: height; right: phase) of Re-DIAN: $\mathrm{C}_{60}$ blends with different ratio: (a) Re-DIAN: $\mathrm{C}_{60}=1: 1$; (b) Re-DIAN: $\mathrm{C}_{60}=1: 9$; (c) Re-DIAN: $\mathrm{C}_{60}=9: 1$. The full scale of all images are $1 \mu \mathrm{m}$ $\times 1 \mu \mathrm{m}$.

convex shape. These results clearly demonstrate the importance of $\mathrm{C}_{60}$ in the exciton dissociation process. Although Re-DIAN itself is also a good hole and electron carrier, the electron transport process is still dominated by the $\mathrm{C}_{60}$ molecules, which has an electron carrier mobility of 1.3 $\mathrm{cm}^{2} \mathrm{~V}^{-1} \mathrm{~s}^{-1} \cdot 15$

Efficient charge separation and transport strongly rely on even dispersion of Re-DIAN and $\mathrm{C}_{60}$. Figure 3 shows the tapping mode atomic force microscopy (AFM) images of different Re-DIAN: $\mathrm{C}_{60}$ blends $(50 \mathrm{~nm})$ coated on ITO substrates. All the samples were prepared by vacuum deposition on unheated substrate, and it is expected that there is no significant difference between bulk and surface morphologies. Phase contrast AFM image provides information on the difference in viscoelasticity between materials. It was used to study the miscibility of blends in polymer photovoltaic cells. $^{16-18}$ The thin film with $1: 1$ ratio [Fig. 3(a)] exhibits features of approximately $30 \mathrm{~nm}$ in size, and its phase image clearly indicates that the "peaks" are of different chemical nature from the surrounding "valleys." Since the exciton diffusion length in organic materials is typically small, such small feature size would facilitate exciton separation and subsequently yield higher efficiency. All samples have relatively small roughness and the height and phase images show clearly that no significant aggregation is formed by either one type of molecules. These observations suggest that the rhenium complex and fullerene molecules are highly compatible with each other.

In conclusion, efficient multilayer bulk heterojunction photovoltaic devices with simple structures were fabricated based on a chlorotricarbonyl rhenium diimine complex with low band gap and good processibility. The active layer consists of a blend of rhenium complex and fullerene that were co-deposited by vacuum sublimation. The rhenium complex acts as both photosensitizer and exhibits bipolar charge transport character. Improved performance can also be achieved by optimizing the thickness of each layer and fabrication of more sophisticated devices.

The work reported in this letter is substantially supported by the Research Grants Council of the Hong Kong Special Administrative Region, China (Project Nos. HKU 7096/00P, $7075 / 01 \mathrm{P}$, and 7096/02P). Partial financial support from the Committee on Research and Conference Grants (University of Hong Kong) is also acknowledged.

${ }^{1}$ C. W. Tang, Appl. Phys. Lett. 48, 183 (1986); G. Yu, J. Gao, J. Hummelen, F. Wudl, and A. J. Heeger, Science 270, 1789 (1995).

${ }^{2}$ P. Peumans, A. Yakimov, and S. R. Forrest, J. Appl. Phys. 93, 3693 (2003).

${ }^{3}$ W. K. Chan, X. Gong, and W. Y. Ng, Appl. Phys. Lett. 71, 2919 (1997); L. S. M. Lam, W. K. Chan, A. B. Djurisic, and E. H. Li, Chem. Phys. Lett. 362, 130 (2002)

${ }^{4}$ X. Gong, P. K. Ng, and W. K. Chan, Appl. Phys. Lett. 75, 3920 (1999).

${ }^{5}$ G. Knör, M. Leirer, T. E. Keyes, J. G. Vos, and A. Vogler, Eur. J. Inorg. Chem. 2000, 749.

${ }^{6}$ R. Argazzi, C. A. Bignozzi, T. A. Heimer, F. N. Castellano, and G. J. Meyer, Inorg. Chem. 33, 5741 (1994).

${ }^{7}$ L. Sacksteder, A. P. Zipp, E. A. Brown, J. Streich, J. N. Demas, and B. A. DeGraff, Inorg. Chem. 29, 4335 (1990).

${ }^{8}$ P. M. Borsenberger, J. Appl. Phys. 68, 6263 (1990).

${ }^{9}$ P. Peumans and S. R. Forrest, Appl. Phys. Lett. 79, 126 (2001); J. J. M. Halls, K. Pichler, R. H. Friend, S. C. Moratti, and A. B. Holmes, ibid. 68, 3120 (1996).

${ }^{10}$ B. A. Gregg, J. Phys. Chem. B 107, 4688 (2003).

${ }^{11}$ I. G. Hill, A. Kahn, Z. G. Soos, and R. A. Pascal, Jr., Chem. Phys. Lett. 327, 181 (2000)

${ }^{12}$ N. Armaroli, Photochem. Photobiol. Sci. 2, 73 (2003).

${ }^{13}$ T. Stübinger and W. Brütting, J. Appl. Phys. 90, 3632 (2001).

${ }^{14}$ P. Peumans, V. Bulovic, and S. R. Forrest, Appl. Phys. Lett. 76, 2650 (2000).

${ }^{15}$ G. Priebe, B. Pietzak, and R. Könenkamp, Appl. Phys. Lett. 71, 2160 (1997).

${ }^{16}$ M. Granström, L. Petritsch, A. G. Arias, A. Lux, M. R. Andersson, and R. H. Friend, Nature (London) 395, 257 (1998).

${ }^{17}$ M. G. Nava, S. Setayesh, A. Rameau, P. Masson, and J.-F. Nierengarten, New J. Chem. 26, 1584 (2002).

${ }^{18}$ S. E. Shaheen, C. J. Brabec, N. S. Sariciftci, F. Padinger, T. Fromherz, and J. C. Hummelen, Appl. Phys. Lett. 78, 841 (2001). 